\title{
AVALIAÇÃO DE ATRIBUTOS DE LATOSSOLO BRUNO E DE TERRA BRUNA ESTRUTURADA DA REGIÃO DE GUARAPUAVA, PARANÁ, POR MEIO DE SUA ENERGIA REFLETIDA ${ }^{(\mathbf{1})}$
}

\author{
J . A. M. DE MATTÊ(2) \& G. J . GARCIA(3)
}

\begin{abstract}
RESUMO
Este trabalho teve por objetivo estudar espectralmenteamostras de L atossolo Bruno e Terra Bruna Estruturada, provenientes de rochas vulcânicas ácidas na região Centro Sul do estado do Paraná, nas profundidades de 0-20 e 40-60 cm. F oram realizadas a caracterização, discri minação e previ são dos atri butos desses solos por meio de sua energia refletida, obtidas em laboratório, pelo sensor IRIS, na faixa espectral de 400 a $2.500 \mathrm{~nm}$. Foi possível discriminar os solos pela intensidade de reflectância e feições de absorção, apesar de apresentarem altos teores de óxidos de ferro, matéria orgânica e textura muito argilosa. A análise discriminante foi $\mathbf{1 0 0 \%}$ eficiente na separação dos solos por sua energia refletida. A gibbsita, a matéria orgânica, a CTC ea tonalidade e a intensidade da cor foram os atributos dos solos que apresentaram equações múltiplas com coeficientes de correlação mais elevados, para sua previsão, por meio da energia refletida.
\end{abstract}

Termos de indexação: reflectância, química e física de solos, mi neralogia de solos, sensoriamento remoto.
SUMMARY: EVALUATION OF ATTRIBUTES OF A HAPLOHUMOX AND A TROPOHUMULT FROM GUARAPUAVA, PARANÁ, BY REFLECTED ENERGY

The objective of this work was to study the spectral reflectance of a Brown Latosol (Haplohumox) and "Terra Bruna Estruturada" (Tropohumult) devel oped from vol canic acid rocks which occur in the center-south region of Paraná, Brazil. These soil samples were

(1) Parte da Tese de Doutorado, apresentada pelo primeiro autor a Escola Superior de Agricultura Luiz de Queiroz - ESALQ/USP, em 6 de abril de 1995, Piracicaba (SP). Recebido para publicação em julho de 1996 e aprovado em dezembro de 1998.

(2) Professor Doutor do Departamento de Sol os e Nutrição de Plantas, ESALQ/USP. Caixa postal 9, CEP 13418-900 Piracicaba (SP). E-mail: jamdemat@carpa.ciagri.usp.br.

(3) Professor Titular do Departamento de Cartografia, UNESP. Caixa Postal 178, CEP: 13 506-700 Rio Claro (SP). 
col lected at depths of 0-20 and 40-60 cm. Thecharacterization, discrimi nation and estimation of the soil attributes were studied by their reflected energy determined at the wavelength interval of 400 to $2.500 \mathrm{~nm}$ using an IRIS Iaboratory spectroradiometer. It was possibl eto separateboth soils using their reflectance intensity and absorption features, al though both soils had high iron, organic matter content and a clayey texture. Discriminant analyses were $100 \%$ effectivein theseparation of soils by their spectral refl ectance. Theresults, which wereanalysed by linear multivariateequations, indicated that gibbsite, organic matter, CEC and the valueand chroma soil col or were the attributes presenting the highest correlation coefficients for their estimation by using spectral reflectance.

Index terms: reflectance, soil chemistry and physics, soil mineralogy, Haplohumox and Tropohumult, remote sensing.

\section{NTRODUÇÃO}

O sensoriamento remoto tem sido considerado importante ferramenta nos mais diversos aspectos relacionados com a agronomia e, em particular, com os estudos de solos. Nesta área, mel hor entendimento tem sido buscado nas relações existentes entre as curvas espectrais e as características específicas dos sol os que permitam sua discriminação e caracterização.

Neste sentido, estudos visam correlacionar as particularidades das curvas espectrais com as características pertinentes ao sol o como a textura, o teor de matéria orgânica, a mineral ogia das diversas frações, à semel hança de Mathews et al. (1973), Stoner \& Baumgardner (1981); K osmas et al . (1984); Coleman et al. (1991), al ém de outros autores.

Por outro lado, há necessidade de se conhecer adequadamente o comportamento da energia refletida de sol os tropicais, considerando os poucos estudos nesta área; no Brasil, citam-se os trabal hos de Formaggio (1983); E piphanio et al. (1992); Formaggio et al. (1996). Além disso, a quantificação de atributos do solo por meio dos dados de reflectância tem sido pouco explorada, daí a necessidade do seu desenvolvimento. Nesta linha, podem-se citar os trabal hos de Coleman et al . (1991, 1993), que, utilizando modelos estatísticos, procuraram quantificar alguns atributos dos solos por meio de sua energia refletida.

Com o advento de novos sensores e com a intensificação da utilização da tecnologia na agricultura, o desenvolvimento de técnicas de sensoriamento remoto aplicadas ao estudo dos sol os torna-se importante. Nesse aspecto, a avaliação do comportamento espectral dos solos poderia auxiliar mais rapidamente a obtenção de informações relativas à sua caracterização.

Pretendeu-se, neste trabalho, caracterizar o comportamento espectral de amostras de L atossolo Bruno eTerra Bruna Estruturada, provenientes de rochas vulcânicas ácidas da região de Guarapuava, estado do Paraná, na faixa espectral de 400 a $2.500 \mathrm{~nm}$, em laboratório, verificando as influências de alguns atributos físicos, quími cos e mineralógicos na energia refletida. Usando equações lineares múltiplas obtidas com os dados de reflectância, buscou-se verificar a quantificação de atributos desses solos. Supõe-se que, apesar de os solos mostrarem altos teores de ferro, matéria orgânica e textura muito argilosa, haverá diferenças espectrais.

\section{MATERIAL E MÉTODOS}

Solos eárea de estudo - As amostras estudadas pertencem a solos classificados como Latossolo Bruno (LB - Haplohumox) e Terra Bruna Estruturada (TB - Tropohumult), provenientes de rochas vulcânicas ácidas (Riolito), localizadas na região Sul do estado do Paraná, entre as latitudes $51^{\circ} 16^{\prime}$ e $51^{\circ} 40^{\prime} \mathrm{S}$ eas longitudes $25^{\circ} 09^{\prime}$ e $25^{\circ} 30^{\prime} \mathrm{WGr}$. Tal região tem, Guarapuava como município principal, numa área com dimensão de $1.451,5 \mathrm{~km} 2$ eestá localizada no Planal to de Guarapuava, fazendo parte do Terceiro Planalto ou Planal to do Trapp do Paraná. As rochas pertencem à formaçãoSerra Geral do grupo São Bento.

Coleta e preparo das amostras de solo e obtenção de curvas espectrais - F oram col etadas amostras nas profundidades de $0-20 \mathrm{~cm}$ ( 15 amostras) e de 40-60 cm (cinco amostras) de sol os previamente reconhecidos por meio de checagem no mapa (escala 1:300.000, EMBRAPA, 1984), da posição no relevo, das tradagens e exames de perfis. Posteri ormente, as amostras foram secas em estufa a $45^{\circ} \mathrm{C}$, por $24 \mathrm{~h}$, sendo destorroadas e passadas por uma peneira de 2 milímetros.

Utilizou-se o espectrorradiômetro I nfra Red Intelligent Spectroradiometer em laboratório, com resolução de $2 \mathrm{~nm}$ entre 400 e $1.100 \mathrm{~nm}$ e $4 \mathrm{~nm}$ entre 1.100 e $2.500 \mathrm{~nm}$. A geometria para aquisição dos dados encontra-se na figura 1 . Foi utilizada como padrão uma placa spectralon cinza, com $50 \%$ de 
reflectância. Posteriormente, os dados foram corrigidos para reflectância de $100 \%$. A razão entre o fluxo radiante espectral refletido pela superfície de uma amostra e ofluxo radiante espectral refletido pel o material de referência, iluminado e visado nas mesmas condições quea superfície da amostra, gera o "fator de reflectância bidirecional". Para cada amostra foram realizadas duas medições, sendo utilizado o valor médio.

Análises químicas, granulométricas e mineralógicas - As análises químicas do solo constam de $\mathrm{pH}\left(\mathrm{CaCl}_{2}\right)$, teor de matéria orgânica, fósforo, potássio, magnésio, cálcio, alumínio e hidrogênio mais alumínio, segundo método descrito em Raij \& Quaggio (1983). A matéria orgânica foi caracterizada pel o fracionamento químico de acordo com o método de Dabin (1971). Foram determi nados os teores de areia grossa, areia fina, silte e argila (Camargo et al., 1986). A sílica, a alumina e o ferro foram determinados pelo ataque sulfúrico (Camargo et al., 1986). A determinação do ferro amorfo foi feita após tratamento com solução ácida de oxalato de amônio (Mckeagne \& Day, 1966). No texto etabelas, o termo "ferro livre" refere-se ao somatório do "ferro livre + ferro amorfo", obtido após tratamento com solução de ditionito-citrato-bicarbonato de sódio (Holmgren, 1967).

Foram realizadas análises mineralógicas para as frações areia, silte e argila de acordo com J ackson (1969). Essa análise consistiu de um pré-tratamento para el iminação dos agentes cimentantes, dentreeles a matéria orgânica (usando água oxigenada a 30\%) e os óxi dos de ferro (tratamento com ditionito-citratobicarbonato de sódio). A seguir, procedeu-se à separação granulométrica em fração areia, por meio da tamisagem úmida, em frações silte e argila, por meio de decantação. As amostras das frações siltee areia, depois de secas, foram colocadas em portaamostra especial, não orientadas eforam irradiadas no intervalo de 2 a 60 $2 \theta$ num aparel ho de raios- $x$, usando-se tubo de cobre e filtro de níquel. Amostras da fração argila desferrificada foram separadas em duas subfrações. Uma delas sofreu saturação por K+ (usando $\mathrm{KCl}$ ) em diversas lavagens e a outra subfração por $\mathrm{Mg}{ }^{2+}$ (usando $\mathrm{MgCl}_{2}$ ).

Após a remoção do excesso de cloretos, as amostras saturadas por $\mathrm{K}+\mathrm{e} \mathrm{Mg}^{+2}$ foram transferidas para lâminas de vidros, e orientadas por meio de esfregaço, e irradiadas por raios- $X$, no intervalo de 2 a $3202 \theta$, também usando-se tubo de cobre com filtro de níquel. As amostras K+saturadas, após a irradiação, sofreram diversos tratamentos a 350 e $550^{\circ} \mathrm{C}$ e foram irradiadas no mesmo intervalo anterior. As amostras $\mathrm{Mg}^{2+}$ saturadas foram irradiadas no mesmo intervalo, porém, pré-tratadas com etileno glicol. Tais tratamentos foram necessários para auxiliar no reconhecimento dos diversos minerais da fração argila.
A identificação da goethita e hematita foi feita em amostras tratadas com $\mathrm{NaOH} 5 \mathrm{M}$ a quente por 1 hora (Kämpf \& Schwertmann, 1982). Após o preparo, as amostras foram irradiadas com raios- $X$, usando tubo de cobre, eos minerais foram identificados principalmente pelos picos relativos a $d_{012}$ e $d_{110}$ respectivamente, hematita e goethita. A proporção desses minerais foi estimada de acordo com a método descrito por Schwertmann \& Lathan (1986).

A determinação semiquantitativa da caulinita e gibbsita foi realizada pela análise térmica diferencial, usando curvas de cali ibração preparadas com padrões de misturas de caulinita e gibbsita (Dixon, 1966). Os outros minerais existentes na fração argila foram estimados percentual mente pela equação: [Outros Minerais g kg-1 $=1.000$ - (caulinita + gibbsita + óxidos de ferro)], dentre os quais se encontram principal mentea vermiculita cloritizada, montmorilonita, traços de mica e material amorfo de sílica e alumina, dependendo do solo.

Métodos estatísticos - A base dos procedimentos estatísticos utilizados neste trabalho refere-se ao programa denominado Statistical Analysis System (SAS, 1989a,b). Foram selecionadas 13 faixas de comprimento de onda entre 400 e $2.500 \mathrm{~nm}$, baseadas em dois critérios: a. nas faixas de reflectância em quea água, a matéria orgânica, ferro, caulinita e gibbsita causam absorção de energia; b. nas faixas que não possuem bandas deabsorção, mas que são influenciadas pelos atributos dos solos em termos deintensi dade (Figura 1). Para aval iação das equações múltiplas, foram utilizados, simultaneamente, os coeficientes $R^{2}$ e $C(p)$. Quando $C(p)$ for maior que o número defaixas espectrais seleci onadas que participam da equação, ela pode ser considerada tendenciosa.

\section{RESULTADOS E DISCUSSÃO}

\section{Caracterização dos solos}

Tanto a Terra Bruna Estruturada (TB) como o Latossolo Bruno (LB) são solos profundos, bem drenados, variando de Bruno-Escuros a Bruno, no horizonte superficial, a bruno forte, no horizonte $B$, muito argiloso tanto na superfície como na subsuperfície (Quadro 1). O rel evo da TB é ondulado a forte ondulado, enquanto o do LB é ondulado. As densidades de drenagem da TB e do LB estão na faixa de 8,4 e 3,6 respectivamente, posicionando-se entre a Terra Roxa Estruturada e o Brunizém Avermel hado (Demattê \& Demétrio, 1996). Quimicamente, são solos predomi nantementeálicos e a saturação por bases é muito baixa para a TB e baixa para o LB (Quadro 2). O teor de matéria orgânica é el evado, na faixa de $50 \mathrm{~g} \mathrm{~kg}^{-1}$, e se deve às condições cl imáticas mais amenas, o que favorece sua acumulação (Buol et al., 1980). 

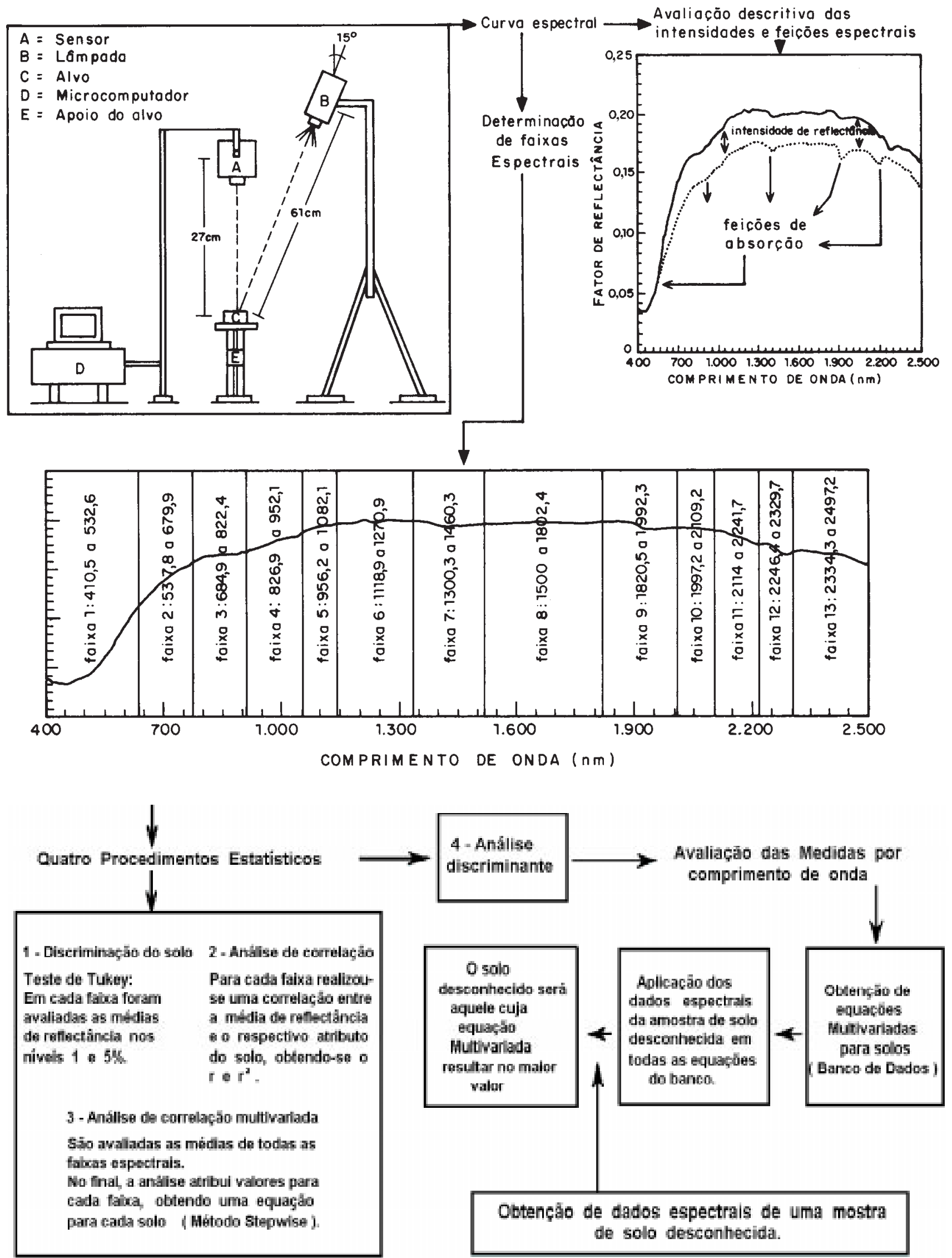

Figura 1. Fluxograma ilustrativo da obtenção e avaliação dos dados espectrais. 
Quadro 1. Resultados médios ${ }^{(1)}$ das análises granulométricas, cor úmida, formas de ferro e matéria orgânica

\begin{tabular}{|c|c|c|c|c|c|c|c|c|c|c|c|c|c|}
\hline \multirow[b]{2}{*}{ Profundidade } & \multicolumn{4}{|c|}{ Granulometria } & \multirow{2}{*}{$\begin{array}{l}\text { Cor }^{(2)} \\
\text { úmida } \\
\text { dominante }\end{array}$} & \multicolumn{4}{|c|}{ Ferro } & \multicolumn{4}{|c|}{ Matéria orgânica (ácidos) ${ }^{(6)}$} \\
\hline & Areia & Silte & Argila & $\begin{array}{l}\text { Silte/ } \\
\text { argila } \\
\times 100\end{array}$ & & $\begin{array}{c}\mathrm{Fe}_{2} \mathrm{O}_{3} \\
\text { total }^{(3)}\end{array}$ & Amorfo $^{(4)}$ & Livre $^{(5)}$ & $\begin{array}{l}\text { Amorfo/ } \\
\text { livre } \\
\times 100\end{array}$ & $\begin{array}{l}\text { Húmico } \\
\text { (Pirofos }\end{array}$ & $\begin{array}{l}\text { Fúlvico } \\
\text { fato } \mathrm{Na} \text { ) }\end{array}$ & $\begin{array}{r}\text { Húmico } \\
\text { ( } \mathrm{Na}\end{array}$ & $\begin{array}{l}\text { Fúlvio } \\
\mathrm{OH)}\end{array}$ \\
\hline \multirow[t]{2}{*}{$\mathrm{cm}$} & \multicolumn{4}{|c|}{$\mathrm{g} \mathrm{kg}^{-1}$} & & 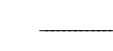 & - & 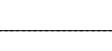 & $g \mathrm{k}$ & & & & \\
\hline & \multicolumn{13}{|c|}{ Latossolo Bruno } \\
\hline \multirow[t]{2}{*}{$\begin{array}{r}0-20 \\
40-60\end{array}$} & $\begin{array}{l}50 \\
40\end{array}$ & $\begin{array}{l}180 \\
140\end{array}$ & $\begin{array}{l}760 \\
820\end{array}$ & $\begin{array}{l}240 \\
180\end{array}$ & $\begin{array}{r}5 Y R \quad 3 / 3 \\
2.5 Y R \quad 3 / 4\end{array}$ & $\begin{array}{l}177 \\
178\end{array}$ & $\begin{array}{l}3,8 \\
3,7\end{array}$ & $\begin{array}{l}110,7 \\
109,1\end{array}$ & $\begin{array}{l}34 \\
34\end{array}$ & $\begin{array}{c}95,1 \\
-\end{array}$ & $\begin{array}{c}52,7 \\
-\end{array}$ & $\begin{array}{c}35,8 \\
-\end{array}$ & $\begin{array}{c}16,6 \\
-\end{array}$ \\
\hline & \multicolumn{13}{|c|}{ Terra Bruna Estruturada } \\
\hline $\begin{array}{r}0-20 \\
40-60\end{array}$ & $\begin{array}{l}40 \\
50\end{array}$ & $\begin{array}{l}220 \\
180\end{array}$ & $\begin{array}{l}740 \\
770\end{array}$ & $\begin{array}{l}300 \\
230\end{array}$ & $\begin{array}{l}\text { 10YR 2/2 } \\
10 Y R \text { 3/4 }\end{array}$ & $\begin{array}{l}135 \\
125\end{array}$ & $\begin{array}{l}4,7 \\
4,4\end{array}$ & $\begin{array}{l}93,1 \\
84,8\end{array}$ & $\begin{array}{l}50 \\
51\end{array}$ & $\begin{array}{l}3,0 \\
-\end{array}$ & $\begin{array}{c}97,0 \\
-\end{array}$ & $\begin{array}{c}78,8 \\
-\end{array}$ & $\begin{array}{c}38,0 \\
-\end{array}$ \\
\hline
\end{tabular}

(1) 15 observações para a camada de 0-20 cm e cinco para a de $40-60 \mathrm{~cm}$. (2) cor de acordo com Munsell Color Charts, Baltimore, Maryland, U.S.A., 1954. (3) Ferro total: extraído pelo ataque sulfúrico. ${ }^{(4)}$ Ferro amorfo: extraído pelo oxalato de amônio. ${ }^{(5)}$ Ferro livre: extraído pel o ditionito citrato bicarbonato de sódio, representado pel o ferro livre + ferro amorfo. ${ }^{(6)}$ fracionamento químico da matéria orgânica. Os ácidos húmicos e fúlvicos foram avaliados pelos métodos do pirofosfato de $\mathrm{Na}$ e $\mathrm{NaOH}$.

Quadro 2. Resultados médios ${ }^{(1)}$ das análises químicas e mineralógicas de amostras de solos

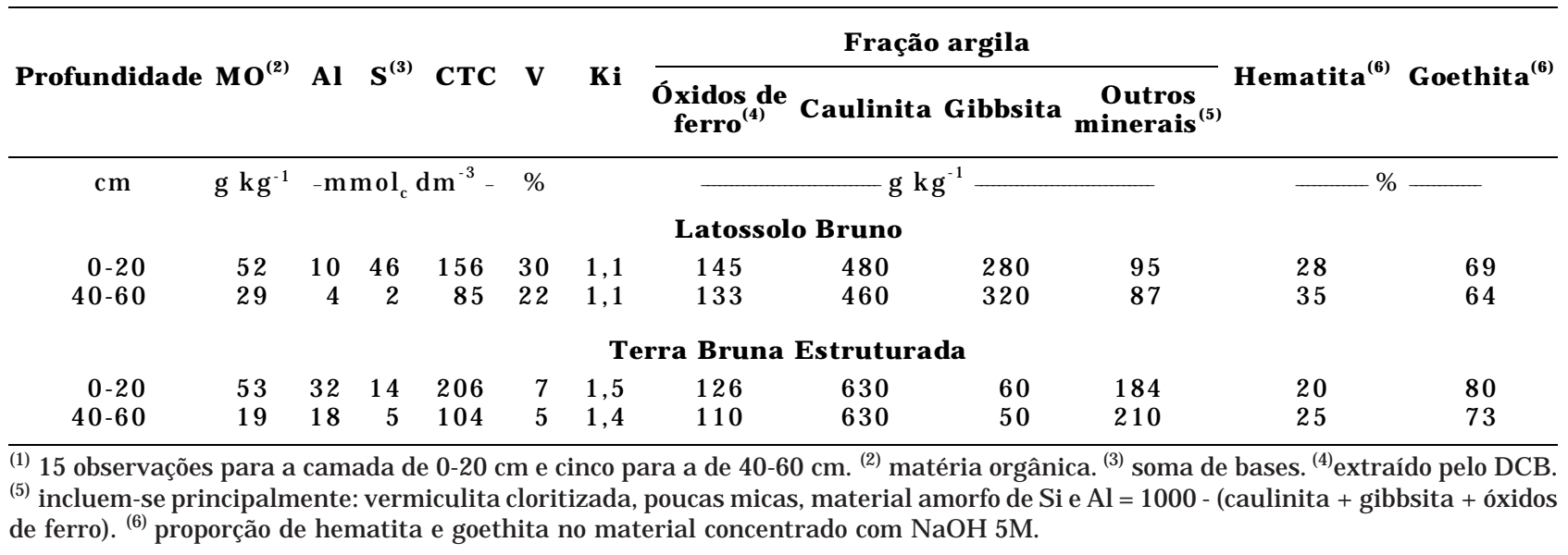

Mineralogicamente, a TB écaulinítica, enquanto o LB, além desse mineral, tem na gibbsita um percentual razoável, na faixa de $300 \mathrm{~g} \mathrm{~kg}^{-1}$ (Quadro 2). Além desses minerais, a difração de raios-X indicou a presença de vermiculita cloritizada e traços de mica e montmorilonita, estes para a TB. Os valores do Ki da TB são ligeiramente superiores aos do LB, indicando ser este solo mais intemperizado. O teor de ferro total está na faixa dos $177 \mathrm{~g} \mathrm{~kg}^{-1}$ para oLB e130 $\mathrm{g} \mathrm{kg}^{-1}$ para aTB (Quadro 1).

As análises de raios- $X$ das frações silte e areia (dados não apresentados) indicaram dominância de quartzo para ambos os solos, porém com pi cos pouco intensos de plagioclásios identificados na fração silte da TB, assim como traços de minerais 2:1.
Em relação aos óxidos de ferro, há dominância de goethita, 69\% para o LB e $80 \%$ para a TB (Quadro 2), val ores estes compatíveis com os obtidos por Rodrigues (1984).

\section{Interpretação dos espectros de reflectância}

Observou-se que entre os sol os TB eLB ocorreram diferenças na magnitude da reflectância e nas feições de absorção de energia el etromagnética em praticamente toda a faixa espectral estudada (Figura 2).

\section{Cor}

Para a cor úmida, o matiz da camada superficial édominantemente 5YR para oLB e10YR para a TB (Quadro 1), havendo aí maior contribuição do 
amarelo no matiz. A TB apresenta tonalidade e intensidade com valor 2 na camada superficial, enquanto no LB é de 3. Na caracterização quantitativa da cor do solo, recomenda-se o uso da faixa do espectroóptico entre 380 e 720 nm (K ristof et al., 1980). Donzeli (1984) verificou que uma variação no matiz, como a aqui verificada, foi suficiente para diferenciar solos na região de Araras.

Em relação aos sol os aqui estudados, notou-seque a intensidade da reflectância émaior no LB a partir dos $550 \mathrm{~nm}$ (Figura 2). Nesse caso, as diferenças observadas estão relacionadas com as propriedades de reflectância da matéria orgânica e óxidos deferro (entre outros) que influenciam a cor. Por sinal, o matiz, valor e croma da cor apresentaram correlação significativa com a reflectância na faixa do visível (Quadro 5), concordando com regressões realizadas por Post et al. (1994).

\section{Matéria Orgânica}

A região de Guarapuava, com clima úmidoe frio, é propícia à acumulação da matéria orgânica. Os solos apresentaram teores de matéria orgânica semel hantes na primeira camada, sendo de $52 \mathrm{~g} \mathrm{~kg}^{-1}$ para o LB (29 na segunda camada) e de $53 \mathrm{~g} \mathrm{~kg}^{-1}$ (19 na segunda camada) para a TB (Quadro 2). Todavia, Henderson et al. (1992) mostraram que os constituintes da matéria orgânica também podem aumentar ou diminuir a intensidade de reflectância, como é o caso dos ácidos fúlvicos e húmicos, respectivamente. $O$ fracionamento da matéria orgânica feito em amostras dos horizontes superficiais mostrou (Quadro 1) que os teores dos áci dos fúlvicos e húmicos extraídos com o pi rofosfato de sódio não indicaram diferenças. Entretanto, a extração feita com o hidróxido de sódio revel ou que a TB apresentou praticamente duas vezes mais ácidos fúlvicos e húmicos em relação ao LB.

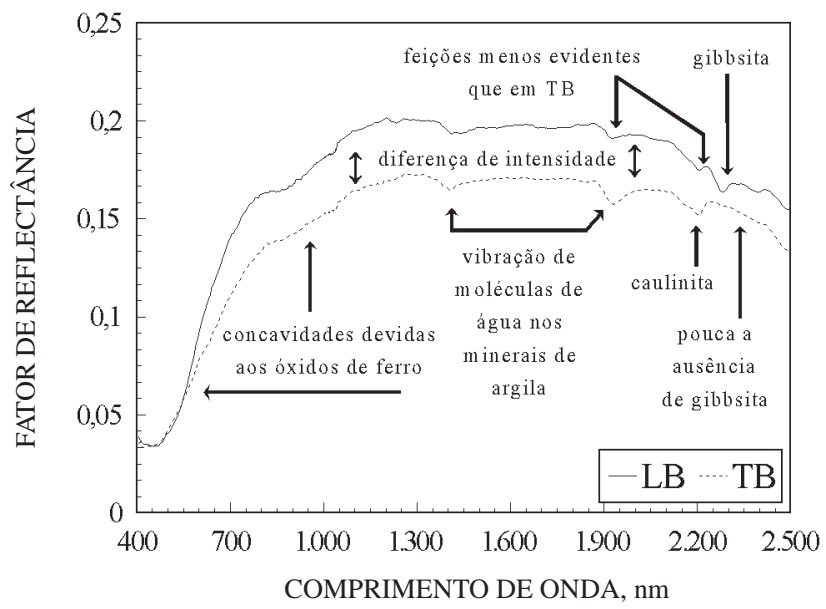

Figura 2. Curvas espectrais médias da camada de $0-20 \mathrm{~cm}$ do Latossolo Bruno (LB); e da Terra Bruna Estruturada (TB).
Por essa razão, os elementos que compõem a matéria orgânica podem ter contribuído nas diferenças de reflectância (Figura 2) entre 400 e 1.200 nm (faixa de atuação da matéria orgânica, de acordo com Mathews et al., 1973), concordando com Henderson et al. (1992).

Além disso, as curvas do LB apresentaram forma convexa-côncava-convexa na faixa entre 400 e $1.200 \mathrm{~nm}$, mostrando que, apesar dos altos teores de matéria orgânica, o efeito do ferro ainda aparece na curva espectral (Figura 3a). Ao contrário, as amostras da TB, com menor teor de ferro em relação ao LB, apresentaram principalmente um formato retilíneo, indicando efeito maior da matéria orgânica (Figura 3b).

O aumento da reflectância na camada com menos matéria orgânica vai de 500 a $1.350 \mathrm{~nm}$ no LB e de 400 a $1.550 \mathrm{~nm}$ na TB (Figura 4), concordando com Mathews et al. (1973). O incremento da intensidade de reflectância da primeira para a segunda camada da TB, em comparação com o LB, deve-se ao menor teor de matéria orgânica desta segunda camada da TB. Além disso, sobressaiu o efeito do ferro, aumentando a concavidade e convexidade entre 400 e $1.200 \mathrm{~nm}$.

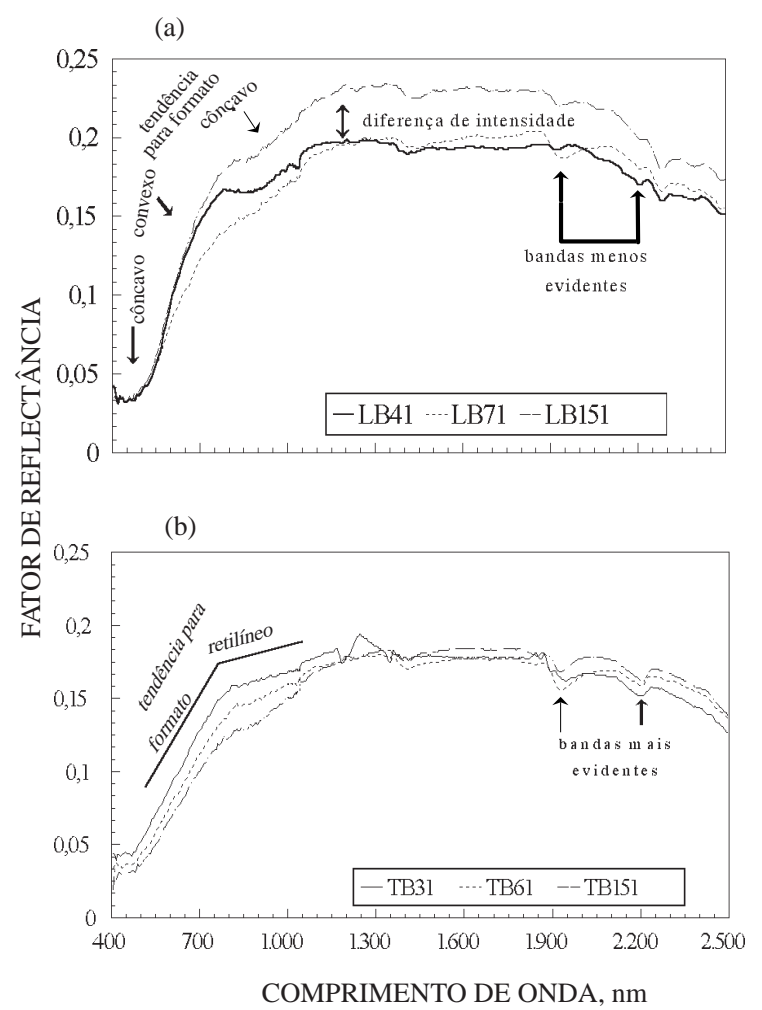

Figura 3. Curvas espectrais individuais de amostras do Latossolo Bruno (LB) e da Terra Bruna E struturada (TB) da camada de 0-20 cm. Teores de argila $\left(\mathrm{g} \mathrm{kg}^{-1}\right)$ : LB41 (76); LB71 (61); LB 151 (78); TB31 (72); TB61 (71); TB151 (76). 
(a)

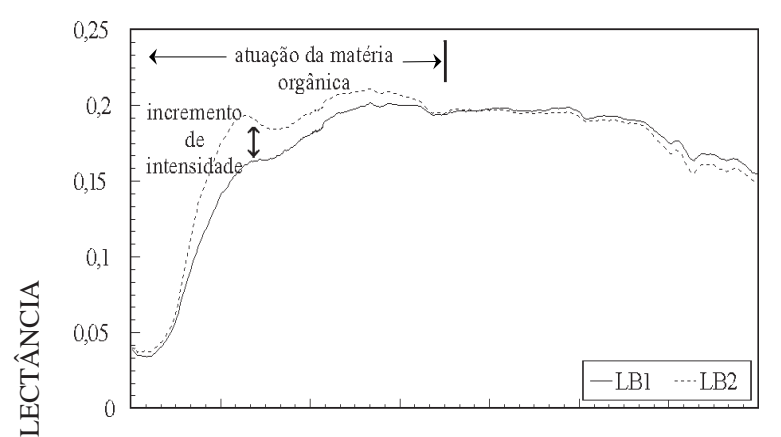

(b)

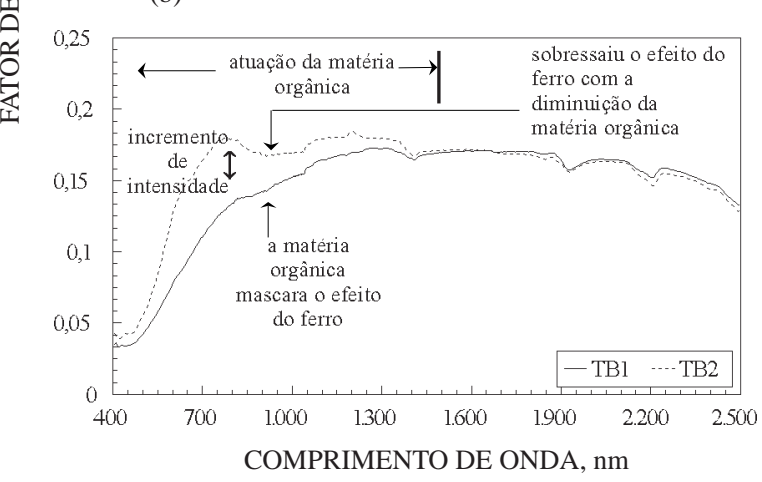

Figura 4. Curvas espectrais médias: (a) LB, Latossolo Bruno, (b) TB, Terra Bruna Estruturada. Designações: LB1, TB1: amostras da profundidade de 0-20 cm; LB2, TB2: amostras da profundidade de $40-60 \mathrm{~cm}$.

\section{Granulometria}

Outra característica a ser explorada para explicar os comportamentos espectrais de LB eTB na figura 2 é a textura, uma vez que o tamanho das partículas de minerais tende a influenciar a reflectância (Bowers \& Hanks, 1965). Os solos apresentaram classe textural muito argilosa, LB com $760 \mathrm{~g} \mathrm{~kg}^{-1} \mathrm{e}$ TB com $740 \mathrm{~g} \mathrm{~kg}^{-1}$ (Quadro 1), e, por essa razão, não deveria haver diferenças nas curvas de reflectância em virtude desse parâmetro. Entretanto, o LB contém percentual maior deargila fina, variação de 12 a $19 \%$ a mais, quando comparado com a TB (Quadro 3). Tal diferença poderia ser mais um fator a estar influenciando as diferenças espectrais desses solos. Isso, entretanto, deve ser considerado com cuidado uma vez que outros fatores associados à textura podem influir na reflectância.

As demais frações granulométricas também devem ser consideradas numa anál ise como esta. Os dois solos aqui estudados apresentam semel hança nos teores de areia, faixa de $50 \mathrm{~g} \mathrm{~kg}^{-1}$ para ambos os solos (Quadro 1) e, portanto, tal fração não deveter influenciado as variações espectrais. O teor de silte, por sua vez, pode ter agido no comportamento das
Quadro 3. Granulometria da fração argila de quatro amostras do Latossolo Bruno e da Terra Bruna Estruturada

\begin{tabular}{|c|c|c|c|}
\hline $\begin{array}{c}\text { Repetição } \\
\text { número }\end{array}$ & $\begin{array}{l}\text { Argila total } \\
(<2 \mu \mathrm{m})\end{array}$ & $\begin{array}{l}\text { Argila grossa } \\
(2-0,2 \mu \mathrm{m})\end{array}$ & $\begin{array}{l}\text { Argila fina } \\
(<0,2 \mu \mathrm{m})\end{array}$ \\
\hline & \multicolumn{3}{|c|}{$\mathrm{g} \mathrm{kg}^{-1}$} \\
\hline \multicolumn{4}{|c|}{ Latossolo Bruno } \\
\hline 1 & 780 & 400 & 380 \\
\hline 2 & 790 & 430 & 360 \\
\hline 3 & 810 & 420 & 390 \\
\hline 4 & 750 & 340 & 410 \\
\hline \multicolumn{4}{|c|}{ Terra Bruna Estruturada } \\
\hline 1 & 780 & 590 & 190 \\
\hline 2 & 820 & 580 & 240 \\
\hline 3 & 740 & 470 & 270 \\
\hline 4 & 730 & 510 & 220 \\
\hline
\end{tabular}

curvas espectrais, pois seus teores são distintos. Para Montgomery et al. (1972), tanto o teor de silte como a presença de minerais intemperizáveis nessa fração tiveram influência na reflectância espectral. As análises mineralógicas dessas frações feitas com difração de raios-X indicaram a presença dominante de quartzo, principalmente no LB com alguma contribuição também de caulinita e plagioclásio na TB. A maior concentração de quartzo pode ter influenciado o aumento da reflectância (Hunt \& Salisbury, 1970) do LB (Figura 2) em todo o espectro óptico. Portanto, devem ser avaliados não só o teor de areia, silte ou argila, mas também os minerais constituintes.

\section{Mineralogia}

A curva espectral da goethita apresenta uma concavidade mais estreita entre 400 e $600 \mathrm{~nm}$ quando comparada com a de hematita, além de absorver menos energia, figura $5 a$ (Vitorello \& Galvão, 1996). A figura 5b indica as curvas do LB e TB em comparação com as curvas de solos desenvolvidos de rocha básica estudados por Demattê (1995).

Os teores de goethita para ambos os solos (Quadro 2) estão na faixa dos 69 e 80\%, respectivamente, LB e TB, para o horizonte superficial, e 64 e $73 \%$, para o horizonteinferior. Tais resultados sãosuperiores aos dos sol os desenvolvidos de rochas básicas, que apresentam, de modo geral, teores de hematita superiores a 60\% (Costa, 1996).

Assim sendo, a curva espectral indicada na figura 5b para os solos TB e LB apresenta uma concavidade na faixa de 400 a $500 \mathrm{~nm}$ mais estreita, quando comparada com as curvas dos solos desenvolvidos de rochas básicas incluídos para comparação neste estudo. Além disso, os sol os ricos 
(a)

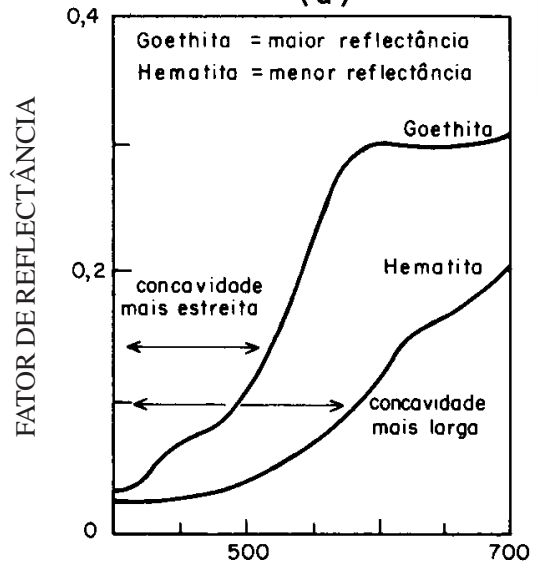

(b)

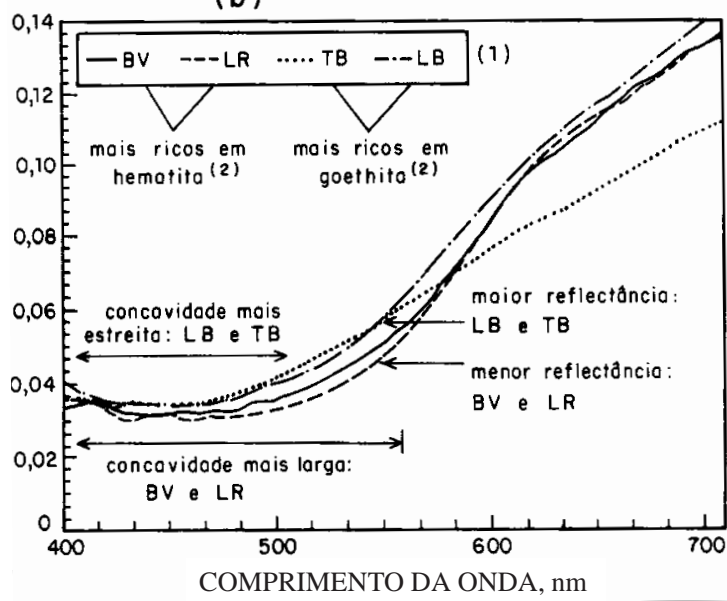

(1) LB : Latossolo Bruno

TB: Terro Bruno Estruturodo BV: Brunizem Avermelhodo LR : Latossolo Roxo

(1) As curvas espectrois de LBe TB forom obtidas no presente trabaiho

(1) As curvos de BV e LR forom obfidos por Dematte (1995)

${ }^{(2)}$ Estas informacōes sōo de Clemente (1988) e Costo (1996).

Observação: As curvas da hematita e da goethita foram extraídas de Vitorello \& Galvão (1996), com exceção das legendas.

Figura 5. Avaliação das curvas da hematita e da goethita e sua relação com as curvas espectrais dos solos.

em goethita evidenciam intensidade de reflectância maior que os hematíticos entre 400 e 570 nm, concordando parcialmente com Kosmas et al. (1984), para os quais a hematita absorve mais energia que a goethita entre 380 e $800 \mathrm{~nm}$. Tudo indica, portanto, que, nesta faixa espectral, as alterações nas curvas espectrais tenham a influência em razão do maior predomínio da goethita.

Contudo, além desses minerais, as formas deferro, no caso o ferro amorfo, também podem influenciar a intensidade de reflectância, conforme relatado por Karmanova (1981). Considerando que o LB apresenta teor de ferro extraído pelo ataquesulfúrico de $177 \mathrm{~g} \mathrm{~kg}^{-1}$, maior que o da TB com $135 \mathrm{~g} \mathrm{~kg}^{-1}$, era para haver maior absorção de energia pel o LB, o que não ocorreu na faixa espectral entre 400 e 1.200 nm (F igura 2). Portanto, considerando quea quantidade Fe-amorfo aumenta do LB $\left(3,8 \mathrm{~g} \mathrm{~kg}^{-1}\right)$ para a TB $\left(4,7 \mathrm{~g} \mathrm{~kg}^{-1}\right)$ (Quadro 1), provavel mente esta forma de ferro seja mais um fator a interferir na diferença da reflectância.

Em relação às bandas de absorção, notou-se que o teor de "outros minerais" decresce na seqüência TB (184 g kg-1) para LB (95 g kg-1), como também o teor de caulinita passa de $630 \mathrm{~g} \mathrm{~kg}^{-1}$ para $480 \mathrm{~g} \mathrm{~kg}^{-1}$. A gibbsita ocorre principalmente no LB, solo mais intemperizado com valor médio de $280 \mathrm{~g} \mathrm{~kg}^{-1}$ (Quadro 2). Essas diferenças influíram na reflectância espectral e estão ilustradas nas figuras 2 e 3.

Os resultados difratométricos na TB mostraram dominância de caulinita, ocorrendo também a vermiculita-cloritizada (mineral com espaçamento de $14 \AA$ e pouco expansivo) etraços demontmorilonita e mica. A gibbsita foi identificada, porém em pouca quantidade. A vermi culita cloritizada absorve menos água do que a montmorilonita e mais água do que as micas (minerais 2:1 com $10 \AA \AA$ ), como observado por Barnhisel (1977). Portanto, as feições de absorção nas curvas de reflectância da TB em 1.400 nm com absorção fraca em 2.200 nm com absorção moderada devem-se à presença da hidroxila estrutural da caulinita, de acordo com Mathews et al. (1973). Considerando que a análise de raios-X identificou a presença da vermiculita-cloritizada e traços de minerais 2:1, provavel menteas feições em $1.400 \mathrm{~nm}$ e $1.920 \mathrm{~nm}$, absorção moderada e forte, devem-seàs vibrações dos grupos $\mathrm{OH}$ e das moléculas de água adsorvidos nesses minerais (Figuras 2 e 3 ).

No LB, as faixas de absorção da caulinita são menos evidentes (Figuras 2 e 3 ) do que na TB, porém a absorçãoem $2.265 \mathrm{~nm}$ indica a presença de gibbsita (Madeira Netto, 1996), mas não na TB, confirmado pela análise de raios-X eanálise térmica diferencial, sendo, portanto, o principal fator de diferenciação com a curva espectral da TB.

\section{Correlação estatística entre dados espectrais e analíticos de solos para as amostras de camada superficial}

As correl ações entre os atributos do sol o ea curva espectral podem ocorrer em determinada faixa ou num conjunto de faixas, assim como em níveis de significância variáveis. Tal fato se deveà influência dos atributos do solo ao longo da curva espectral (Coleman et al., 1991). N o caso do LB, o cál ci o teve a melhor correlação na faixa 1 (Quadro 4) mas também tevesignificância a 5\% nas faixas 5, 6, 7, 11 e 12 (dados não apresentados).

Os parâmetros "soma de bases" e "saturação por bases" e os elementos cálcio, magnésio e potássio apresentaram correlação positiva para o LB (Quadro 4). Tais resultados vêm de encontro às observações de Demattê et al. (1998). Tais autores verificaram um aumento na intensidade de 
reflectância em quase todo o espectro óptico, em função do aumento do teor de cálcio nos solos desenvolvidos de rochas ácidas. Neste caso, o LB apresentou maior teor de bases, na faixa de $46 \mathrm{mmol}_{\mathrm{c}} \mathrm{dm}^{-3}$, assim como maior variação, contra $14 \mathrm{mmol}_{\mathrm{c}} \mathrm{dm}^{-3}$ para a TB (Quadro 2), sugerindo que, a partir de determinado nível, o teor de bases age nesta faixa espectral. Nesse caso, o maior teor de bases trocáveis no LB corresponde a mais um fator que pode ter contribuído na diferença da magnitude espectral desses solos.

A correlação de determinado atributo do solo como o fósforo, com significância a 1\% para o LB e ausência de correlação na TB, pode ser devida aos níveis de valores encontrados para cada solo
(Coleman et al., 1991). Outro ponto a ser considerado refere-se à variação das faixas espectrais de determinado atributo em relação aos diferentes solos. Assim é o caso do potássio, com correlação significativa a $1 \%$ para ambos os solos na faixa 12 para o LB e na faixa 5 para a TB. Tais resultados evidenciam que os solos possuem características próprias, e daí a possibilidade de terem para um mesmo atributo faixas diferenciadas de correlação com a reflectância.

Quando se examinam os dados estatísticos envolvendo os dois solos em conjunto (Quadro 5), o número de observações aumenta para 30. Dos 23 parâmetros analisados, 16 tiveram significância a 1\% e 7 parâmetros a $5 \%$ em pelo menos uma faixa espectral.

Quadro 4. Faixas de comprimento de onda que apresentaram coeficientes de correlação mais elevados com os atributos $^{(1)}$ dos solos (As amostras do Latossolo Bruno e da Terra Bruna Estruturada foram consideradas individualmente)

\begin{tabular}{|c|c|c|c|c|c|}
\hline \multicolumn{3}{|c|}{ Latossolo Bruno (n: 15) } & \multicolumn{3}{|c|}{ Terra Bruna Estruturada (n: 15) } \\
\hline Atributo & $\mathbf{r}$ & Faixa(2) & Atributo & $\mathbf{r}$ & Faixa(2) \\
\hline Fósforo & 0,780 & $12 *$ & Matiz & $-0,750$ & $9 * *$ \\
\hline V & 0,673 & $1 * *$ & Potássio & 0,738 & $5 * *$ \\
\hline Cálcio & 0,618 & $1 *$ & M.O. & 0,661 & $13^{* *}$ \\
\hline SB & 0,590 & $1 *$ & Valor & 0,607 & $1 *$ \\
\hline Valor & 0,590 & $2 *$ & F e-amorfo/F e-livre & 0,588 & $5^{*}$ \\
\hline CTC efetiva & 0,531 & $1 *$ & & & \\
\hline Magnésio & 0,529 & $1 *$ & & & \\
\hline $\mathrm{CTC}_{1}$ & $-0,519$ & $2 *$ & & & \\
\hline Croma & 0,509 & 3* & & & \\
\hline Potássio & 0,585 & $12^{* *}$ & & & \\
\hline
\end{tabular}

(1) Siglas: V: saturação por bases; SB: soma de bases; m.o.: matéria orgânica; Fe-am.: ferro amorfo extraído pelo oxalato; Fe-liv.: extraído pelo ditionito citrato bicarbonato de sódio. Representa o ferro livre +ferro amorfo; CTC $_{1}$ : capacidade de troca de cátions do solo; $\mathrm{n}$ : número de observações. ${ }^{(2)}$ Faixa 1, 2...13: faixas de comprimento de onda selecionadas; * , ** : significância a 5 e 1\%, respectivamente.

Quadro 5. Faixas de comprimento de onda e coeficientes de correlação mais elevados com os atributos ${ }^{(1)}$ dos solos (Análise estatística usando dados dos dois solos em conjunto, n: $\mathbf{3 0}^{(2)}$ )

\begin{tabular}{|c|c|c|c|c|c|}
\hline Atributo & $\mathbf{r}$ & F aixa ${ }^{(3)}$ & Atributo & $\mathbf{r}$ & Faixa ${ }^{(3)}$ \\
\hline $\mathrm{CTC}_{1}$ & $-0,721$ & $3 * *$ & $\mathrm{CTC}_{2}$ & $-0,556$ & $3 * *$ \\
\hline Matiz & $-0,706$ & $3 * *$ & Fe-amorfo/livre & $-0,544$ & $3 * *$ \\
\hline Fe-total & 0,651 & $3 * *$ & Valor & 0,529 & $2 * *$ \\
\hline $\mathrm{V}$ & 0,642 & $5 * *$ & $\mathrm{Ki}$ & $-0,521$ & $3^{*}$ \\
\hline Croma & 0,631 & $3 * *$ & Cálcio & 0,519 & $5 * *$ \\
\hline Gibbsita & 0,620 & $3^{*}$ & Outros minerais & $-0,517$ & $3 * *$ \\
\hline Caulinita & $-0,607$ & $3 * *$ & Silte & $-0,456$ & 9* \\
\hline Fósforo & 0,586 & $5 * *$ & Fe-amorfo & $-0,440$ & 3* \\
\hline Potássio & 0,571 & $8 * *$ & CTC efetiva & 0,412 & $11 *$ \\
\hline SB & 0,557 & $6 * *$ & Silte/argila & $-0,386$ & $2 *$ \\
\hline Magnésio & 0,557 & $6 * *$ & M.O. & $-0,362$ & $1 *$ \\
\hline Fe-livre & 0,557 & $3 * *$ & & & \\
\hline
\end{tabular}

Siglas: V: saturação por bases; SB: soma de bases; m.o.: matéria orgânica; Fe-am.: ferro amorfo extraído pel o oxalato; Fe-liv.: extraído pelo ditionito citrato bicarbonato de sódio. Representa o ferro livre + ferro amorfo; $\mathrm{CTC}_{1}$ : capacidade de troca de cátions do solo; $\mathrm{CTC}_{2}$ : capacidade de troca de cátions da argila; outros minerais: incluem-se principalmente a vermiculita cloritizada, poucas micas, material amorfo deSi eAl; ${ }^{(2)}$ número de observações; ${ }^{(3)}$ faixa $1,2 \ldots$...13: faixas de comprimento de onda sel ecionadas ;* , ** : significância a 5 e $1 \%$, respectivamente. 
A correlação da gibbsita (faixa 3) indica que na medi da em que aumenta o seu teor no solo aumenta a intensidade de reflectância. No caso dos perfis do $\mathrm{LB}$, a variação deste mineral vai de 150 a $450 \mathrm{~g} \mathrm{~kg}^{-1}$ enquanto na TB vai de 40 a $100 \mathrm{~g} \mathrm{~kg}^{-1}$ (dados não apresentados). Madeira Netto (1996) obteve correl açãosignificativa entrea intensidade da banda de absorção da gibbsita e a concentração deste mineral. Tal resultado obtido para a gibbsita não deixa deser animador, pois pode auxiliar na seleção de bandas do espectro para possíveis estudos de previsão das variáveis dos sol os, como aliás tem sido feito por Coleman \& Montgomery (1987).

O matiz, valor echroma apresentaram significância a $1 \%$ nas faixas de um a três correspondentes ao visível do espectro el etromagnético, dados estes semel hantes aos obtidos por Mathews et al. (1973), concordando com Kristof et al. (1980).

Quanto à matéria orgânica, com correlação negativa na faixa um, os resul tados são concordantes com os obtidos por Coleman \& Montgomery (1987) que trabal haram com Alfisols eV ertisols.

\section{Discrimi nação ecaracterização espectral de solos}

Os dois solos foram discriminados estatisticamente nas faixas 3 a 13 (entre 684 e $2.500 \mathrm{~nm}$ ) com significância a $1 \%$, não tendo as faixas 1 e 2 (entre 410 e $679 \mathrm{~nm}$ ) contribuído para a diferenciação dos solos.

Com o objetivodedesenvolver etestar métodos para a determi nação do tipo de sol o e sua separabilidade, foram realizadas análises discriminantes a partir de dados espectrais ou de dados analíticos. Para tanto, foram obtidas equações discriminantes (Quadro 6) com os dados espectrais para caracterizar os solos. Pressupondo o conhecimento das reflectâncias médias por faixa de comprimento de onda de um desses dois tipos de solos sem que se saiba qual é o solo, esses dados devem ser aplicados nas equações dos dois solos. Aquela que resultar em mai or val or, terá maior probabilidade de representar o solo desconhecido (Figura 1). Tanto pelos dados analíticos dos solos, como pela reflectância espectral, essas equações foram testadas apresentando $100 \%$ de eficiência de classificação, mesmo apresentando semel hanças nos teores dematéria orgânica, textura eferro. Coleman et al. (1991) chegarama obter erros de até 55,6\%, provavel mente pela heterogeneidade da amostragem para um mesmo solo.

\section{Previsão dos atributos dos solos pela sua energia refletida}

As estimativas das características dos solos por meio dos dados espectrais para os mais diversos usos não deixam de ser importante ferramenta de trabalho de aplicação do sensoriamento remoto, como já evidenciaram Coleman \& Montgomery (1987); Coleman et al. (1991) e Demattê \& Garcia (1999) por meio de model os estatísticos.

Os dados do quadro 7 resumem as sel eções das melhores combinações de faixas do espectro óptico para obtenção das equações de acordo com as características dos solos. Assim, oteor de fósforo pode ser estimado através das faixas espectrais 7,11 e 12 com $R^{2}$ de 0,76 , porém com $C(p)$ igual a 77 , maior que o número de bandas usadas na equação, indicando tendenciosidade. O melhor resultado foi para a previsão da matéria orgânica na TB que apresentou $R^{2}$ de 0,92 significância a $1 \%$ e com baixo $C(p)$. O R 2 médio para todas as equações foi de 0,49 ,

\section{Quadro 6. Equações lineares discriminantes em função da reflectância e os respectivos testes de discriminância}

\begin{tabular}{|c|c|c|c|c|}
\hline Solo(1) & \multicolumn{4}{|c|}{ Equação linear discriminante ${ }^{(2)}$} \\
\hline Latossolo Bruno & \multicolumn{4}{|c|}{$\begin{array}{l}-139,11+370 \mathrm{~F}_{1}-1032 \mathrm{~F}_{2}-836,99 \mathrm{~F}_{3}+575,24 \mathrm{~F}_{4}+1142 \mathrm{~F}_{5}+2626 \mathrm{~F}_{6}-717,74 \mathrm{~F}_{7}-2394 \mathrm{~F}_{8}+ \\
+949,61 \mathrm{~F}_{9}-1478 \mathrm{~F}_{10}-1147 \mathrm{~F}_{11}-1326 \mathrm{~F}_{12}+4135 \mathrm{~F}_{13}\end{array}$} \\
\hline \multirow[t]{4}{*}{ Terra Bruna Estruturada } & \multicolumn{4}{|c|}{$\begin{array}{l}-132,15+3347 \mathrm{~F}_{1}-810,71 \mathrm{~F}_{2}-2525 \mathrm{~F}_{3}+2800 \mathrm{~F}_{4}+497,69 \mathrm{~F}_{5}+1935 \mathrm{~F}_{6}+1752 \mathrm{~F}_{7}-4325 \mathrm{~F}_{8}- \\
-250,21 \mathrm{~F}_{9}+772,94 \mathrm{~F}_{10}-3573 \mathrm{~F}_{11}+1297 \mathrm{~F}_{12}+2939 \mathrm{~F}_{13}\end{array}$} \\
\hline & \multicolumn{4}{|c|}{ Resultados da classificação, \% } \\
\hline & \multicolumn{2}{|c|}{ Dados espectrais } & \multicolumn{2}{|c|}{ Dados analíticos } \\
\hline & Acerto & Erro & Acerto & Erro \\
\hline Latossolo Bruno & 100,0 & 0,0 & 100,0 & 0,0 \\
\hline Terra Bruna Estruturada & 100,0 & 0,0 & 100,0 & 0,0 \\
\hline
\end{tabular}

(1) 15 observações para cada solo. ${ }^{(2)} F_{1}, F_{2}, F_{3} \ldots F_{13}$ : faixas de comprimento de onda selecionadas. 


\section{Quadro 7. Equações lineares múltiplas relacionando os atri butos ${ }^{(1)}$ dos solos com a reflectância média de bandas espectrais selecionadas para os dois tipos de solos (Latossolo Bruno e Terra Bruna Estruturada)}

\begin{tabular}{|c|c|c|c|}
\hline Atributo & E quação de regressão(2) & $\mathbf{R}^{2}$ & $C(p)$ \\
\hline \multicolumn{4}{|c|}{ L atossolo Bruno (n:15) } \\
\hline Cálcio & $\hat{\mathrm{Y}}=10\left(24,55+706,96 \mathrm{~F}_{1}\right)$ & $0,382 *$ & $-0,11$ \\
\hline Croma & $\hat{\mathrm{Y}}=5,42-360,81 \mathrm{~F}_{1}+85,37 \mathrm{~F}_{3}$ & $0,454 *$ & $-4,27$ \\
\hline СТC1 & $\hat{\mathrm{Y}}=10\left(30,61-158,24 \mathrm{~F}_{2}\right)$ & $0,269 *$ & 267,07 \\
\hline CTC efetiva & $\hat{\mathrm{Y}}=10\left(29,93+925,90 \mathrm{~F}_{1}\right)$ & $0,281^{*}$ & 2,26 \\
\hline Potássio & $\hat{\mathrm{Y}}=10\left(-0,33+21,67 \mathrm{~F}_{12}-19,51 \mathrm{~F}_{13}\right)$ & $0,524 *$ & 303,75 \\
\hline Fósforo & $\hat{\mathrm{Y}}=-65,70+383,64 \mathrm{~F}_{7}-1264,23 \mathrm{~F}_{11}+1330,11 \mathrm{~F}_{12}$ & $0,758 * *$ & 77,05 \\
\hline Magnésio & $\hat{\mathrm{Y}}=10\left(-15,51+454,48 \mathrm{~F}_{1}\right)$ & $0,280 *$ & 7,44 \\
\hline SB & $\hat{\mathrm{Y}}=10\left(-40,30+1171,37 \mathrm{~F}_{1}\right)$ & $0,343^{*}$ & 2,51 \\
\hline V & $\hat{\mathrm{Y}}=-284,58+8215,29 \mathrm{~F}_{1}$ & $0,453 * *$ & 4,12 \\
\hline Valor & $\hat{\mathrm{Y}}=-1,07+67,24 \mathrm{~F}_{2}-38,81 \mathrm{~F}_{7}+35,20 \mathrm{~F}_{13}$ & $0,601 *$ & $-2,54$ \\
\hline \multicolumn{4}{|c|}{ Terra Bruna E struturada (n:15) } \\
\hline Fe-amorfo/F e-livre & $\hat{\mathrm{Y}}=23,10+178,60 \mathrm{~F}_{5}$ & $0,346 *$ & 8,58 \\
\hline Potássio & $\hat{\mathrm{Y}}=10\left(-0,16+1,70 \mathrm{~F}_{5}^{5}\right)$ & $0,545^{* *}$ & 6,02 \\
\hline Matiz & $\hat{\mathrm{Y}}=6,57-9,99 \mathrm{~F}_{9}$ & $0,562 * *$ & 236,46 \\
\hline M atéria orgânica & $\hat{\mathrm{Y}}=10\left(1,56-15,30 \mathrm{~F}_{5}+121,48 \mathrm{~F}_{10}-308,27 \mathrm{~F}_{12}+237,40 \mathrm{~F}_{13}\right)$ & $0,921 * *$ & 0,79 \\
\hline Valor & $\hat{\mathrm{Y}}=2,97+94,91 \mathrm{~F}_{1}-20,09 \mathrm{~F}_{6}$ & $0,724 * *$ & 19,48 \\
\hline
\end{tabular}

(1) Siglas: SB: soma de bases; Fe-am.: ferro extraído pelo oxalato; Fe-liv.: extraído pelo ditionito citrato bicarbonato de sódio. Representa o ferro livre + ferro amorfo; $\mathrm{CTC}_{1}$ : capacidade de troca de cátions do solo; ${ }^{(2)} \mathrm{F}_{1}, \mathrm{~F}_{2}, \ldots \mathrm{F}_{13}$ : faixas de comprimento de onda selecionadas; n: número de observações; * , ** : significância a 5 e 1\%, respectivamente.

Quadro 8. Equações lineares múltiplas relacionando os atributos ${ }^{(1)}$ dos solos e a reflectância média de bandas espectrais selecionadas para os dois tipos de solos (Latossolo Bruno e Terra Bruna Estruturada), considerados conjuntamente

\begin{tabular}{|c|c|c|c|}
\hline Atributo & E quação de regressão(2) & $\mathbf{R}^{2}$ & $C(p)$ \\
\hline Cálcio & $\hat{\mathrm{Y}}=10\left(-7,26+53,17 \mathrm{~F}_{5}\right)$ & $0,270 * *$ & $-7,16$ \\
\hline Caulinita & $\hat{\mathrm{Y}}=10\left(67,15+895,15 \mathrm{~F}_{1}-331,77 \mathrm{~F}_{3}\right)$ & $0,505^{* *}$ & 21,27 \\
\hline Croma & $\hat{\mathrm{Y}}=-3,01-236,55 \mathrm{~F}_{2}+218,67 \mathrm{~F}_{3}-104,83 \mathrm{~F}_{9}+104,73 \mathrm{~F}_{13}$ & $0,732 * *$ & $-2,65$ \\
\hline СТC1 & $\hat{\mathrm{Y}}=10\left(28,02-106,85 \mathrm{~F}_{3}+333,77 \mathrm{~F}_{12}-319,92 \mathrm{~F}_{13}\right)$ & $0,642 * *$ & $-1,58$ \\
\hline СТC2 & $\hat{\mathrm{Y}}=10\left(14,12+285,39 \mathrm{~F}_{1}-133,40 \mathrm{~F}_{3}\right)$ & $0,372 * *$ & $-4,45$ \\
\hline СTC efetiva & $\hat{\mathrm{Y}}=10\left(-4,82+58,62 \mathrm{~F}_{11}\right)$ & $0,170 *$ & $-6,98$ \\
\hline Fe-amorfo/F e-livre & $\hat{\mathrm{Y}}=27,52+2358,79 \mathrm{~F}_{1}-1694,70 \mathrm{~F}_{2}+520,34 \mathrm{~F}_{3}$ & $0,664 * *$ & 15,58 \\
\hline Fe-total & $\hat{\mathrm{Y}}=10\left(15,08-425,00 \mathrm{~F}_{1}+193,40 \mathrm{~F}_{2}\right)$ & $0,691 * *$ & 12,99 \\
\hline Fe-livre & $\hat{\mathrm{Y}}=10\left(10410-193750 \mathrm{~F}_{1}+83150 \mathrm{~F}_{2}\right)$ & $0,576 * *$ & 7,13 \\
\hline Fe-amorfo & $\hat{\mathrm{Y}}=10\left(364,51+10032,02 \mathrm{~F}_{12}-10167,97 \mathrm{~F}_{13}\right)$ & $0,591 * *$ & 8,32 \\
\hline Gibbsita & $\hat{\mathrm{Y}}=10\left(-10,71+916,92 \mathrm{~F}_{1}-2649,09 \mathrm{~F}_{12}+2741,67 \mathrm{~F}_{13}\right)$ & $0,706 * *$ & 2,27 \\
\hline Potássio & $\hat{\mathrm{Y}}=10\left(-0,11+1,25 \mathrm{~F}_{8}\right)$ & $0,326 * *$ & $-3,80$ \\
\hline Fósforo & $\hat{\mathrm{Y}}=-14,58+108,92 \mathrm{~F}_{5}$ & $0,343^{* *}$ & 4,42 \\
\hline $\mathrm{Ki}$ & $\hat{\mathrm{Y}}=1,66-23,14 \mathrm{~F}_{3}+18,32 \mathrm{~F}_{4}$ & $0,392 * *$ & 7,22 \\
\hline Matiz & $\hat{\mathrm{Y}}=5,07+167,11 \mathrm{~F}_{1}-86,51 \mathrm{~F}_{2}$ & $0,704 * *$ & 65,70 \\
\hline Magnésio & $\hat{\mathrm{Y}}=10\left(-5,95+38,43 \mathrm{~F}_{6}\right)$ & $0,311 * *$ & $-3,82$ \\
\hline Matéria orgânica & $\hat{\mathrm{Y}}=10\left(5,57-47,68 \mathrm{~F}_{1}-16,78 \mathrm{~F}_{5}+26,83 \mathrm{~F}_{12}\right)$ & $0,377 * *$ & 5,82 \\
\hline Outros minerais & $\hat{\mathrm{Y}}=10\left(37,51-536,30 \mathrm{~F}_{3}+414,05 \mathrm{~F}_{4}\right)$ & $0,365^{* *}$ & 0,54 \\
\hline SB & $\hat{\mathrm{Y}}=10\left(-13,11+87,34 \mathrm{~F}_{6}\right)$ & $0,300 * *$ & $-6,32$ \\
\hline Silte/argila & $\hat{\mathrm{Y}}=45,24-129,21 \mathrm{~F}_{3}$ & $0,154 *$ & 2,14 \\
\hline Silte & $\hat{\mathrm{Y}}=10\left(28,12+432,27 \mathrm{~F}_{8}-486,53 \mathrm{~F}_{9}\right)$ & $0,337 * *$ & 1,83 \\
\hline V & $\hat{\mathrm{Y}}=-102,90+718,08 \mathrm{~F}_{5}$ & $0,413^{* *}$ & $-4,51$ \\
\hline Valor & $\hat{\mathrm{Y}}=1,73+87,20 \mathrm{~F}_{4}-70,25 \mathrm{~F}_{5}$ & $0,586 * *$ & $-4,77$ \\
\hline
\end{tabular}

(1) Siglas: SB: soma de bases; Fe-am.: ferro amorfo extraído pelo oxalato; Feliv.: extraído pelo ditionito citrato bicarbonato de sódio.

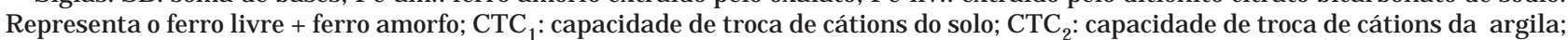
outros minerais: incluem-se princi palmente a vermiculita cloritizada, poucas micas, material amorfo de Si eAl. ${ }^{(2)} \mathrm{F}_{1}, \mathrm{~F}_{2}, \ldots \mathrm{F}_{13}:$ faixas de comprimento de onda sel ecionadas; * , ** : significância a 5 e 1\%, respectivamente. 
oquenão tem diferido muito de outros pesquisadores (Coleman et al., 1991).

Analisando o quadro 6, observa-se que toda a porção do espectro óptico usado foi significativa na determinação das variáveis do solo. Quando foram utilizados dados detodos os sol os (Quadro 8), 21 dos 23 atributos obtiveram significância a 1\%; e 2 a 5\% com $\mathrm{R}^{2}$ médio de 0,48 . Com o aumento do número de observações para 30, surgiram atributos com melhores $\mathrm{R}^{2}$ e C(p), tais como o croma, gibbsita e a CTC do solo. Aliás, a gibbsita apresentou um $\mathrm{R}^{2}$ de 0,70 com C (p) de 2,27, concordando com Madeira Netto (1996) sobre a possibilidade de quantificação desse mineral por meio da reflectância. Apenas para comparação, Col eman et al. (1991) apresentaram R2 máximos de 0,68.

É necessário, entretanto, enfatizar o fato de que tais equações, como muitos outros modelos de previsão, são geograficamentedependentes, podendo ou não ser aplicadas em outras áreas. Para isso, há necessidade de mais pesquisas e observar até que ponto ou em que condições tais model os se aplicam.

\section{CONCLUSÕES}

1. Ocorreram diferenças nas intensidades e feições espectrais entre os dois solos, atribuídas, principalmente, às diferenças dos minerais constituintes das frações areia, silte e argila, dos óxidos de ferro hematita e goethita e ferro amorfo.

2. A reflectância da camada subsuperficial dos solos apresentou maior intensidade em relação à camada superficial entre 500 e $1.550 \mathrm{~nm}$ do espectro el etromagnético, devidos à influência da matéria orgânica.

3. A análise discriminante foi $100 \%$ eficiente na separação dos dois sol os por meio dos dados espectrais.

4. A gibbsita, a matéria orgânica, a CTC, a tonalidade e a intensidade da cor apresentaram equações múltiplas com coeficientes de correlação mais el evados para sua previsão quantitativa.

\section{AGRADECIME NTO}

Ao Instituto Nacional de Pesquisas Espaciais, INPE, Departamento de Sensoriamento Remoto (SERE ), localizado em São J osé dos Campos, pela utilização do espectrorradiômetro IRIS, sem o qual não seria possível a realização deste trabalho.

\section{LITERATURA CITADA}

BARNHISEL, R.I. Chlorites and hydroxy interlayered vermiculite and smectite. In: DIXON, J .B. \& WEED, S.B., eds. Minerals in soil environments. Madison, SSSA, 1977. p.331-56.
BOWERS, S.A. \& HANKS, R.J . Reflectance of radiant energy from soils. Soil Sci., 100:130-138, 1965.

BUOL, S.; HOLE, F.D. \& MC CACKEM, R.F. Soil genesis and classification. Ames, The Iowa University Press, 1980. 4040p.

CAMARGO, O.A.; MONIZ, A.C.; J ORGE, J .A. \& VALADARES, J .M. Métodos de análise química, mineralógica e física de sol os do I AC. Campinas, Instituto Agronômico de Campinas, 1986. 94p. Boletim Técnico, 106.

CLEMENTE, C.A. Alterações e sol os desenvol vidos sobre rochas vulcânicas ácidas da formação Serra Geral nos Planaltos de Guarapuava e Palmas, Região Centro Sul do Estado do Paraná. Piracicaba, Escola Superior de Agricultura “Luiz de Queiroz"/USP, 1988. 211p. (Tese de Doutorado)

COLEMAN, T.L. \& MONTGOMERY, O.L. Soil moisture, organic matter, and iron content effect on the spectral characteristics of selected Vertisols and Alfisols in Alabama. Photogram. Eng. Rem. Sens, 53:1659-1663, 1987.

COLEMAN, T.L.; AGBU, P.A.; MONTGOMERY, O.L.; GAOT, T. $\&$ PRASAD, S. Spectral band selection for quantifying selected properties in highly weathered soils. Soil Sci., 151:355-361, 1991.

COLEMAN, T.L.; AGBU, P.A. \& MONTGOMERY, O.L. Spectral differentiation of soils and soil properties: is it possiblefrom space plataforms? Soil Sci., 155:283-293, 1993.

COSTA, A.C. Iron oxide mineralogy of soils deriveded from volcanic rocks in the Paraná river basim, Brazil. Columbus, Ohio State University, 1996. 243p. (Tese de Doutorado)

DABIN, B. Etude d'une méthode d'extraction de la matière humique du sol. Sci. Sol., 1:47-63, 1971.

DEMATTÊ, J.A.M. Relações entre dados espectrais e características físicas, químicas e mineralógicas de solos desenvolvidos de rochas eruptivas. Piracicaba, Escola Superior deAgricultura “Luiz deQueiroz", 1995. 265p. (Tese de Doutorado).

DEMATTÊ, J .A.M. \& DEMÉTRIO, V.A. Padrões de drenagem em áreas de sol os desenvolvidos de rochas vulcânicas ácidas na região de Guarapuava (PR). R. Bras. Ci. Solo, 20:305311, 1996.

DEMATTÊ, J .A.M.; GARCIA, G.J . \& PROCHNOW, L.I Variações induzidas de atributos químicos e sua influência na reflectância espectral de três solos do estado do Paraná. R. Bras. Ci. Solo, 22:479-490, 1998.

DEMATTÊ, J .A.M. \& GARCIA, G.J . Alteration of soil properties through a weathering sequence as evaluated by spectral reflectance. Soil Sci. Soc. Am. J ., 63:237-342, 1999.

DIXON, J.B. Quantitative analysis of kaolinite and gibbsite in soils by differential thermal and selective dissolution methods. In: CLAYS AND CLAY MINERALS CONFERENCE, 14., New York, 1966. Proceedings. New York, Pergamon Press, 1966. p.82-89.

DONZELI, P.L. Comportamento espectral de três latossolos argil osos da região de Limeira - Araras - SP em relação às suas propriedades físicas e químicas. Piracicaba, Escola Supeiror deAgricultura "Luiz deQueiroz", 1984. 149p. (Tese de Doutorado). 
EMPRESA BRASILEIRA DE PESQUISA AGROPECUÁRIA EMBRAPA. Serviço Nacional de Levantamento e Conservação de Solos. Levantamento de reconhecimento dos solos do Estado do Paraná. Londrina, 1984. t.1. 412p. (Bol etim técnico, 57)

EPIPHANIO,J .C.N.; FORMAGGIO, A.R.; VALERIANO, M.M.\& OLIVEIRA, J.B. Comportamento espectral de solos do Estado de São Paulo. São J osé dos Campos, Instituto Nacional de Pesquisas Espaciais, 1992. 131p.

FORMAGGIO, A.R. Comportamento espectral de quatro solos do Estado de São Paulo nos níveis orbital, de campo e de laboratório. SãoJ osé dos Campos, INPE, 1983. 90p. (Tese de Mestrado)

FORMAGGIO, A.R.; EPIPHANIO,J .C.E.; VALERIANO, M.M.\& OLIVEIRA, J.B. Comportamento espectral (450-2.450 nm) de solos tropicais de São Paulo. R. Bras. Ci. Solo; 20:467$474,1996$.

HENDERSON, T.L.; BAUMGARDNER, M.F.; FRANZMEIER, D.P.; STOTT, D.E. \& COSTER, D.C. High dimensional reflectance analysis of soil organic matter. Soil Sci. Soc. Am. J ., 56:865-872, 1992.

HOLMGREN, G.S. A rapid citrate-dithionite extractable iron procedure. Soil Sci. Soc. Am. Proc., 31:210-211, 1967.

HUNT, G.R. \& SALISBURY, J .W. Visibleand infrared spectra of minerals and rocks: II. Carbona. Modern Geol., 2:2330,1970 .

J ACKSON, M.L. Soil chemical analysis; advanced course. Madison, Wisconsin University, 1969. 895p.

KÄMPF, N. \& SCHWERTMANN, U. The $5 \mathrm{M} \mathrm{NaOH}$ concentration method for iron oxides in soils. Clays Clay Miner., 30:401408, 1982.

KARMANOVA, L.A. Effect of various iron components on the spectral reflectance and color of soils. Sov. Soil Sci., 13:53$60,1981$.

KOSMAS, C.S.; CURI, N.; BRYANT, R.B. \& FRANZMEIER, D.P. Characterization of ironoxide minerals by second-derivative visiblespectroscopy. Soil Sci. Soc. Am. J ., 48:401-405, 1984.

KRISTOF, S.J .; BAUMGARDNER, M.F.; WEISMILLER, R.A.\& DAVIS, S. Application of multiespectral reflectancestudies of soils: Pre-LANDSAT. In: SYMPOSIUM MACHINE PROCESSING OF REMOTELY SENSED DATA, 6., West Lafayette, 1980. Proceedings. West Lafayette, 1980. v.2. p.52-61.
McKEAGNE,J .A. \& DAY, J.H. Dithioniteand oxalateextractable $\mathrm{Fe}$ and $\mathrm{Al}$ as aids in differentiating various class of soils. Can. J . Soil Sci., 46:13-22, 1966.

MADEIRA NETTO, J .S. Spectral reflectance properties of soils. Photo I nterpret., 34:59-72, 1996.

MATHEWS, H.L.; CUNNINGHAM, R.L. \& PETERSEN, G.W. Spectral reflectance of selected Pennsylvania soils. Soil Sci. Soc. Am. Proc., 37:421-424, 1973.

MONTGOMERY, O.L.; BAUMGARDNER, M.F.\& WEISMILLER, W.A. An investigation of the relationship between spectral reflectance and chemical, physical and genetic characteristics of soils. West Lafayette, Purdue University, 1972. (LARS. Information note, 082776)

POST, D.F.; HORVATH, E.H.; LUCAS, W.M.; WHITE, S.A.; EHASZ, M.F. \& BATAHILY, A.K. Relations betwen soil col or and LANDSAT reflectance on semiarid Rangelands. Soil Sci. Soc. Am. J ., 58:1809-16, 1994.

RAIJ , B. van. \& QUAGGIO,J .A. Métodos de análise do sol o para fins de fertilidade. Campinas, Instituto Agronômico de Campinas, 1983. 40p. (Boletim técnico, no 81)

RODRIGUES, T.E. Caracterização e gênese de sol os brunos do Maciço Alcalino de Poços de Caldas (MG). Piracicaba, Escola Superior deAgricultura "Luiz deQueiroz", 1984. 255p. (Tese de Doutorado)

SAS. Statistical Analysis System Institute. SAS/STATr User's guide, version 6, 4.ed. Cary, NC: SAS I nstitute Inc., 1989a. v.1. 943p.

SAS. Statistical Analysis System Institute. SAS/STATr User's guide, version 6, 4.ed. Cary, NC: SAS I nstitute Inc., 1989b. v.2. 846p.

SCHWERTMANN, U. \& LATHAN, M. Properties of iron oxides in some New Caledonian Oxisols. Geoderma, 39:10-123, 1986.

STONER, E.R. \& BAUMGARDNER, M.F. Characteristic variations in reflectance of surface soils. Soil Sci. Soc. Am. J ., 45:1161-1165, 1981.

VITORELLO, I. \& GALVÃO, L.S. Spectral properties of geologic materials in the 400 to $2500 \mathrm{~nm}$ range: review for applications to mineral exploration and lithologic mapping. Photo Interpret., 34:77-99, 1996. 